\title{
Antioxidant activity and duodenum transporter gene expression in quail fed citric acid
}

\author{
T.P. Santana ${ }^{1}$, J.A.S. Jesus ${ }^{1}$, M.S. Bastos ${ }^{1}$, A.S. Nunes ${ }^{1}$, G.M. Oliveira Júnior ${ }^{1}$, \\ C.S. Nascimento ${ }^{1}$, L.T. Barbosa ${ }^{1}$, C.O. Brito ${ }^{1}$, E. Gasparino ${ }^{2} \&$ A.P. Del Vesco ${ }^{1 \#}$ \\ ${ }^{1}$ Universidade Federal de Sergipe, Department of Animal Science. São Cristóvão, Sergipe, Brazil \\ ${ }^{2}$ Universidade Estadual de Maringá, Department of Animal Science. Maringá, Paraná, Brazil
}

(Received 4 January 2019; Accepted 23 May 2019; First published online 9 July 2019)

\author{
Copyright resides with the authors in terms of the Creative Commons Attribution 4.0 South African License. \\ See: http://creativecommons.org/licenses/by/4.0/za \\ Condition of use: The user may copy, distribute, transmit and adapt the work, but must recognize the authors and \\ the South African Journal of Animal Science.
}

\begin{abstract}
The study aimed to evaluate the effects of citric acid supplementation on the performance and the gene expression in the duodenum of Japanese quail. Genes related to antioxidant activity: superoxide dismutase (SOD) and glutathione peroxidase 7 (GPX7); and genes related to nutrient uptake in the enterocytes' apical membrane: sodium-glucose cotransporter 1 (SGLT1, responsible for the glucose absorption), glucose transporter 2 (GLUT2) and $B^{0} A T 1$ (responsible for the absorption of neutral amino acids in brush board membrane) were evaluated. For this, 270 laying quails (Coturnix japonica) were fed a diet supplemented with $0 \%, 0.6 \%$ or $1.2 \%$ of citric acid. Gene expression was evaluated by the quantitative reverse transcription-polymerase chain reaction (qRT-PCR) at 35 days old $(n=5)$. The highest expression of the SGLT1 gene was observed in quails fed the $1.2 \%$ citric acid supplemented diet $(0.120 \mathrm{AU})$. Birds fed diets with both levels of citric acid supplementation showed a higher $B^{O} A T 1$ gene expression than quails fed no citric acid. Quails fed the $1.2 \%$ of citric acid supplemented diet had the lowest $S O D$ gene expression (0.3455 AU). The birds receiving the diets supplemented with citric acid showed a lower GPX7 gene expression than the quails fed the $0 \%$ citric acid diet. These results suggests that the effect of citric acid on gene expression in the digestive tract may have contributed to the greater weight gain and lower feed intake observed in birds fed diets supplemented with citric acid.
\end{abstract}

Keywords: $\mathrm{B}^{0} \mathrm{AT1}$, intestinal health, organic acid, pathogenic microorganisms, SGLT1

\#Corresponding author: apaulavesco@gmail.com

\section{Introduction}

In poultry the gastrointestinal tract (GIT) accommodates many communities of microorganisms that evolved in a complex way within the host. Despite the similarities that are observed in healthy birds, GIT segments have distinct communities, owing to the intrinsic conditions of each segment, such as $\mathrm{pH}$ and nutrient levels (Ranjitkar et al., 2016). The caecum has the greatest variety of microorganisms, being occupied predominantly by mutualist species of the genus, Clostridium. Species belonging to the Lactobacillus genus are predominant in the upper GIT (Gong et al., 2007). Thus, digestion and absorption are carried out in the presence of intestinal microbiota and its products (Jones et al., 2012).

The gastrointestinal mucosa comprises the intestinal epithelium and the lamina propria, which, together with the immune support, act as a barrier between the luminal contents and systemic compartments. In the small intestine, absorption of the final products of carbohydrate and protein digestion takes place in the apical membrane of enterocytes by specific transporters. Glucose uptake occurs by active $\mathrm{Na}+$ dependent transport through the sodium-glucose cotransporter, SGLT1 (Mueckler \& Thornes, 2013). Amino acids are absorbed by carriers that may be classified with regard to sodium dependence, and according to the preferred substrate. Several amino acid transporters have been identified. Among these, $\mathrm{B}^{0} \mathrm{AT} 1$ is a neutral amino acid transporter that is sodium dependent and is present at the brush border $(\mathrm{Wu}$, 2013).

Although the commensal microflora are closely related to some of the functions performed by the GIT, such as intestinal epithelium proliferation, immune activity (Brestoff \& Artis, 2013) and prevention of 
colonization by pathogenic bacteria (Forder et al., 2007), contamination with pathogenic microorganisms can cause intestinal damage, which affects the gut physiological function and causes reduced feed efficiency and increased mortality in poultry. To maintain GIT health, specialized cells that recognize phagocyte pathogens eliminate them under reactive oxygen species (ROS) action. The ROS that are produced to eliminate pathogenic bacteria in turn must be neutralized by antioxidant components. Some of these components are antioxidant enzymes, such as superoxide dismutase (SOD), and the enzymes that are involved in the glutathione complex, such as glutathione peroxidase and glutathione reductase (Paiva \& Bozza, 2014).

The balance among the GIT microorganisms and that between the microorganisms and the host are critical for homeostasis, and therefore the health of the GIT. Thus, additives with possible microbial modulation actions have been studied. Among these, citric acid has been shown to change the intestinal histomorphology and increase villi height, and therefore the absorptive area (Adil et al., 2010). Citric acid can also reduce the microbial population, thus increasing the availability of nutrients for the host (Hassan et al., 2016).

This study was conducted under the hypothesis that citric acid supplementation could alter the composition of the microflora, ensuring intestinal health and thus improve development of birds. Therefore, the present study aimed to evaluate the effects of citric acid supplementation on the expression of genes related to antioxidant activity, namely $S O D$, and GPX7, and genes related to nutrient uptake in the enterocyte apical membrane, such as SGLT1, GLUT2 and $B^{0} A T 1$ in the duodenum of laying quail.

\section{Material and Methods}

This experiment was approved by the Committee on Animal Care of the Universidade Federal de Sergipe (protocol number 09/2015).

A total of 270 female quails (Coturnix japonica) at nine days old $(22.7 \pm 0.9 \mathrm{~g})$ were used in the experiment. The experiment was conducted in a completely randomized design with three treatments, namely the diet supplemented with $0 \%, 0.6 \%$ or $1.2 \%$ citric acid. The animals were separated in collective cages (10 animals per cage), which served as the experimental units $(n=9)$, and were raised under conventional production systems.

During the experimental period, the animals had free access to water and feed. The diet was formulated to meet their nutritional requirements (Rostagno et al., 2011) (Table 1). Feed intake was calculated as the difference between the amount of feed offered at the beginning of the experiment and the residues at the end. Weight gain was calculated as the difference between the weight at the beginning of the experiment (nine-day-old quail) and the weight at the end (35-day-old quail). The feed intakes and the weight gains were corrected for mortality.

For the analyses of gene expression levels, five birds from each treatment was used, chosen on the basis of the average bodyweight of each replicate. Duodenum samples were collected and stored in liquid nitrogen at $-80^{\circ} \mathrm{C}$ pending total RNA extraction.

The total RNA was extracted using Trizol (Invitrogen, Carlsbad, CA, USA) according to the manufacturer's instructions (1 mL per $100 \mathrm{mg}$ tissue). All the materials had previously been treated with the RNase inhibitor RNase AWAY (Invitrogen, Carlsbad, CA, USA). The total RNA concentration was measured with a spectrophotometer at a wavelength of $260 \mathrm{~nm}$. RNA integrity was analysed using a $1 \%$ agarose gel that was stained with SYBR® Safe DNA gel stain (Invitrogen, Carlsbad, CA, USA) and visualized under ultraviolet light (Figure 1). The RNA samples were treated with DNase I (Invitrogen, Carlsbad, CA, USA), according to the manufacturer's instructions, to remove possible genomic DNA contamination.

SuperScript III First-Strand Synthesis Super Mix kit (Invitrogen, Carlsbad, CA, USA) was used for CDNA synthesis according to the manufacturer's instructions. The samples were stored at $-20^{\circ} \mathrm{C}$ until further use. The real-time PCR reactions were performed using the fluorescent dye SYBR GREEN (SYBR GREEN PCR Master Mix, Applied Biosystems, Carlsbad, CA, USA). The primers used in the GLUT2, SGLT1, B ${ }^{0} A T 1$, GPX7 and SOD amplification reactions were designed based on the gene sequences deposited at National Centre for Biotechnology Information (NCIBI) (accession numbers Z22932, XM_415247, XM_419056, NM_001163245.1, and NM_205064.1) (Table 2). Two endogenous controls were used, namely $\beta$-actin and GAP D efficient. All the analyses were performed in duplicate, each in a volume of $25 \mu \mathrm{L}$.

The primers used in the gene analysis study proved adequate for real-time PCR analysis. Amplification efficiency was similar for the genes of interest, with $90 \%$ to $110 \%$ efficiency. The analysis of the dissociation curves did not reveal the presence of unspecific products or the formation of primer dimers, which demonstrated the reliability of the data for estimating the mRNA expression of these genes. The $\beta$-actin that was used as the housekeeping gene did not show statistically significant differences across treatments, which demonstrated the validity of its use as the endogenous control. 
Table 1 Percentage composition of experimental diets (expressed on an as-fed basis) for Japanese quails

\begin{tabular}{lccc}
\hline \multirow{2}{*}{ Ingredients (\%) } & \multicolumn{3}{c}{ Levels of citric acid supplementation } \\
\cline { 2 - 4 } & $\mathbf{0 \%}$ & $\mathbf{0 . 6 \%}$ & $\mathbf{1 . 2 \%}{ }^{*}$ \\
\hline Corn, 8.2\% CP & 50 & 50 & 50 \\
Soybean meal, 46.0\% CP & 39.8 & 39.8 & 39.8 \\
Soybean oil & 3.52 & 3.52 & 3.52 \\
DL-methionine 99\% & 0.046 & 0.046 & 0.046 \\
L-lysine HCl 78\% & 0.002 & 0.002 & 0.002 \\
L-threonine 98\% & 0.03 & 0.03 & 0.03 \\
Citric acid & - & 0.6 & 1.2 \\
Salt & 0.398 & 0.398 & 0.398 \\
Premix & 5 & 5 & 5 \\
Inert & 1.2 & 0.6 & - \\
Total & 100 & 100 & 100 \\
Composition (\%) & & & 1200 \\
Citric acid (g/kg) ${ }^{\dagger}$ & 0.0 & 600 & 22 \\
Crude protein (CP) & 22 & 22 & 1.12 \\
Lysine digestible & 1.12 & 1.12 & 0.76 \\
Met+Cys digestible & 0.76 & 0.76 & 0.79 \\
Threonine digestible & 0.79 & 0.79 & 0.26 \\
Tryptophan digestible & 0.26 & 0.26 & 0.96 \\
Calcium & 0.96 & 0.96 & 0.44 \\
Available phosphorus & 0.44 & 0.44 & 0.18 \\
Sodium & 0.18 & 0.18 & 2900 \\
AME (kcal/kg) ${ }^{\ddagger}$ & 2900 & 2900 & \\
& & & \\
\hline
\end{tabular}

*Supplied per kilogram of diet: 10000000 IU retinyl-acetate; 750000 IU cholecalciferol; 36 IU DL- $\alpha$-tocopherol; $625 \mathrm{mg}$ thiamine; $1500 \mathrm{mg}$ riboflavin; $1250 \mathrm{mg}$ pyridoxine; $5000 \mathrm{mg}$ cyanocobalamin; $3000 \mathrm{mg}$ D-pantothenic axid; $50 \mathrm{mg}$ D-biotin; $250 \mathrm{mg}$ folic acid; $6000 \mathrm{mg}$ niacinamide; $75 \mathrm{~g}$ choline chloride; 13 zinc oxide; $12 \mathrm{~g}$ ferrous sulphate; $15 \mathrm{~g}$ manganese sulphate; $2500 \mathrm{mg}$ copper sulphate; $50 \mathrm{mg}$ cobalt sulphate; $250 \mathrm{mg}$ iodine; 1000 mg butyl hydroxy toluene

${ }^{\dagger}$ Values refer only to supplemented citric acid

${ }^{\ddagger}$ AME: apparent metabolizable energy

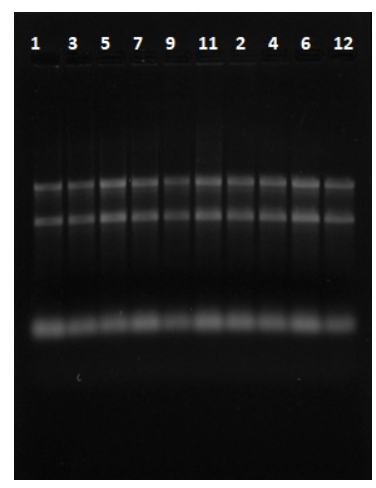

Figure 1 RNA integrity displayed in a denaturing agarose gel The $18 \mathrm{~S}$ and $28 \mathrm{~S}$ ribosomal RNA bands that are clearly visible, show the intact RNA samples 
Table 2 Primer sequences used for quantitative real-time polymerase chain reactions

\begin{tabular}{|c|c|c|c|}
\hline Gene & $\begin{array}{l}\text { Amplicom } \\
\text { (bp) }\end{array}$ & $\begin{array}{c}\text { Annealing } \\
\text { Temperature }\left({ }^{\circ} \mathrm{C}\right)\end{array}$ & Primer sequence (5'-3') \\
\hline GLUT2* & 180 & $60^{\circ} \mathrm{C}$ & $\begin{array}{l}\text { CGCAGAAGGTGATAGAAGC } \\
\text { ACACAGTGGGGTCCTCAAAG }\end{array}$ \\
\hline SGLT1 & 160 & $60^{\circ} \mathrm{C}$ & $\begin{array}{c}\text { GCCATGGCCAGGGCTTA } \\
\text { CAATAACCTGATCTGTGCACCAGTA }\end{array}$ \\
\hline$B^{0} A T 1$ & 153 & $60^{\circ} \mathrm{C}$ & $\begin{array}{l}\text { TCTATTGAAGATTCGGGCAC } \\
\text { AATGGTAAGCACAAGGTATGG }\end{array}$ \\
\hline GPX7 & 140 & $60^{\circ} \mathrm{C}$ & $\begin{array}{l}\text { TTGTAAACATCAGGGGCAAA } \\
\text { TGGGCCAAGATCTTTCTGTAA }\end{array}$ \\
\hline$S O D$ & 126 & $60^{\circ} \mathrm{C}$ & $\begin{array}{l}\text { TGGACCTCGTTTAGCTTGTG } \\
\text { ACACGGAAGAGCAAGTACAG }\end{array}$ \\
\hline$\beta$-actin & 136 & $60^{\circ} \mathrm{C}$ & $\begin{array}{c}\text { ACCCCAAAGCCAACAGA } \\
\text { CCAGAGTCCATCACAATACC }\end{array}$ \\
\hline
\end{tabular}

"GLUT2: glucose transporter 2; SGLT1: sodium-glucose cotransporter; $B^{0} A T 1$ : amino acid transporter; GPX7: glutathione peroxidase 7; SOD: superoxide dismutase

The $2^{-\Delta C T}$ method was used for the relative quantification analysis, and the data were expressed as an arbitrary unit (AU). The results are expressed as averages and standard errors. The Shapiro-Wilk test was applied to evaluate data normality. The experiment was conducted in a completely randomized design with three treatments. Data were analysed by ANOVA, with the treatment effects being regarded as fixed, and the averages were compared using the Tukey test $(P<0.05)$ (SAS Inst. Inc., Cary, NC, USA).

\section{Results}

(a)

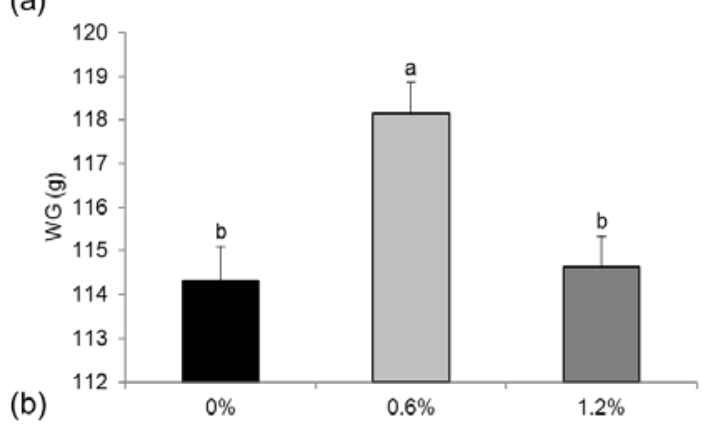

(b)

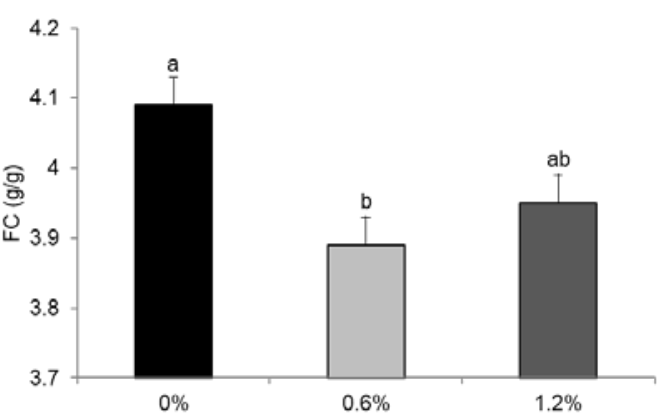

Figure 2 Weight gain (WG) (a) and feed conversion (FC) ratio (b) of quails fed three diets, which contained $0 \%, 0.6 \%$ and $1.2 \%$ of citric acid 
The results of weight gain and feed conversion are presented in Figures $2 a$ and $2 b$, respectively. The greatest weight gain $(P=0.0251)$ and the lowest feed conversion $(P=0.0012)$ were observed in animals fed $0.6 \%$ of citric acid supplemented diet. There was no difference between quails receiving the $0 \%$ and $1.2 \%$ of citric acid in their diets. There was no significant effect of diet on feed intake $(0 \%=462.0,0.6 \%=467.1$ and $1.2 \%$ of citric acid supplementation $=463.6 \mathrm{~g} \mathrm{AU}$ ).

The results of $S G L T 1$ and $B^{\circ} A T 1$ gene expression are presented in Figures $3 \mathrm{a}$ and $3 \mathrm{~b}$, respectively. The greatest expression of the SGLT1 gene was observed in quails fed $1.2 \%$ of citric acid supplementation (0.120 AU, $P<0.0001)$. Animals fed diets containing citric acid showed a higher $(P=0.0003) \mathrm{B}^{0} \mathrm{AT} 1$ gene expression than quails fed the $0 \%$ citric acid diet.

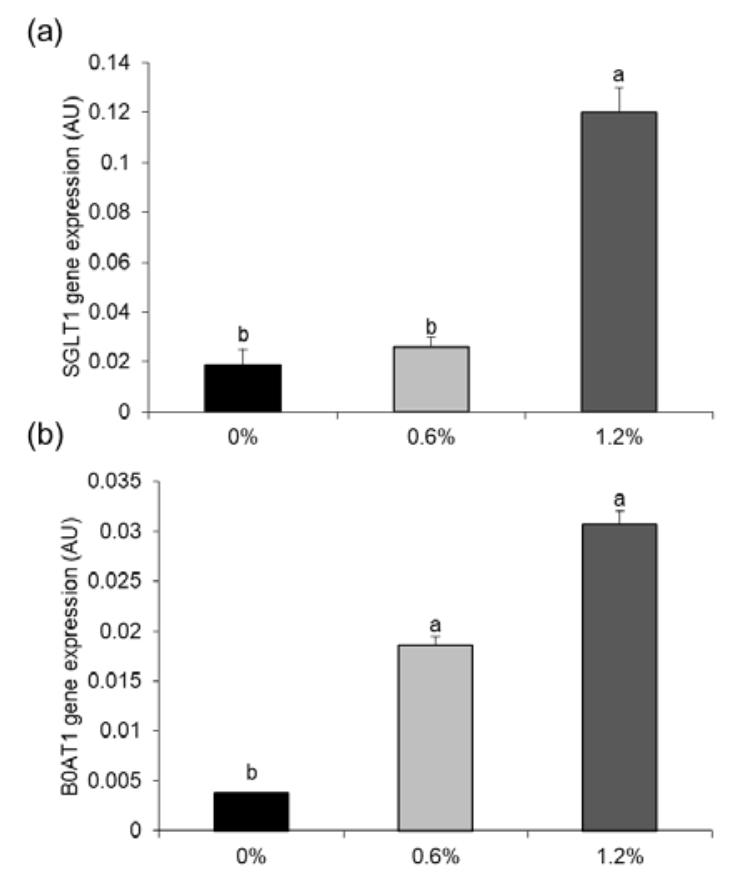

Figure 3 Sodium-glucose cotransporter (SGLT1) (a) and amino acid transporter ( $B^{0} A T 1$ ) (b) gene expression in duodenum of quails fed three diets, namely $0 \%, 0.6 \%$ and $1.2 \%$ citric acid

Quails fed $1.2 \%$ of citric acid supplementation had the lowest SOD gene expression $(0.3455 \mathrm{AU}, P$ $<0.0001$ ) (Figure 4a). Animals fed diets with both levels of citric acid supplementation showed lower GPX7 gene expression than quails fed the $0 \%$ citric acid diet (Figure $4 b$ ).

The treatments did not influence the GLUT2 gene expression $(0 \%=0.0017,0.6 \%=0.0018$, and $1.2 \%$ of citric acid supplementation $=0.020 \mathrm{AU}$ ).

\section{Discussion}

Citric acid has been shown to improve the development of the poultry by altering the intestinal histomorphology by increasing the villi height, and therefore the absorptive area (Adil et al., 2010). Citric acid affects the GIT immune response (Rodríguez-Lecompte et al., 2012) and has an effect on the microbial population in the GIT. The reduction in microbial growth may be related to lower metabolic demands for the tract, thus increasing the availability of nutrients for the host (Hassan et al., 2016). In this study, it was observed that quails fed $0.6 \%$ citric acid supplementation had a $4.5 \%$ higher weight gain and a $3 \%$ better feed conversion ratio than the control. Since there is no diet effect on feed intake, these results can be associated with greater efficiency in the processes of digestion and absorption of nutrients. This could be owing in part to a higher expression of SGLT1 and $B^{0} A T 1$ genes that was observed in the duodenum of quails receiving citric acid supplementation. The intestinal mucosa of birds is arranged anatomically in villi and crypts to increase the area of absorption. The mucosa has cells that produce mucus, cells that produce hormones, and absorptive cells, namely enterocytes (Reece et al., 2015). In the lumen of the small intestine, peptides from protein digestion in the stomach and polysaccharides are broken down by pancreatic enzymes. Final digestion occurs in the brush border membrane by the digestive enzymes. The aminopeptidase enzyme cleaves amino acids at the N-terminus of polypeptides, and sucrose-isomaltase 
cleaves sucrose and isomaltose into glucose and fructose in the membrane. Absorption occurs in the enterocyte apical membrane by specific transporters (Su et al., 2014).

(a)

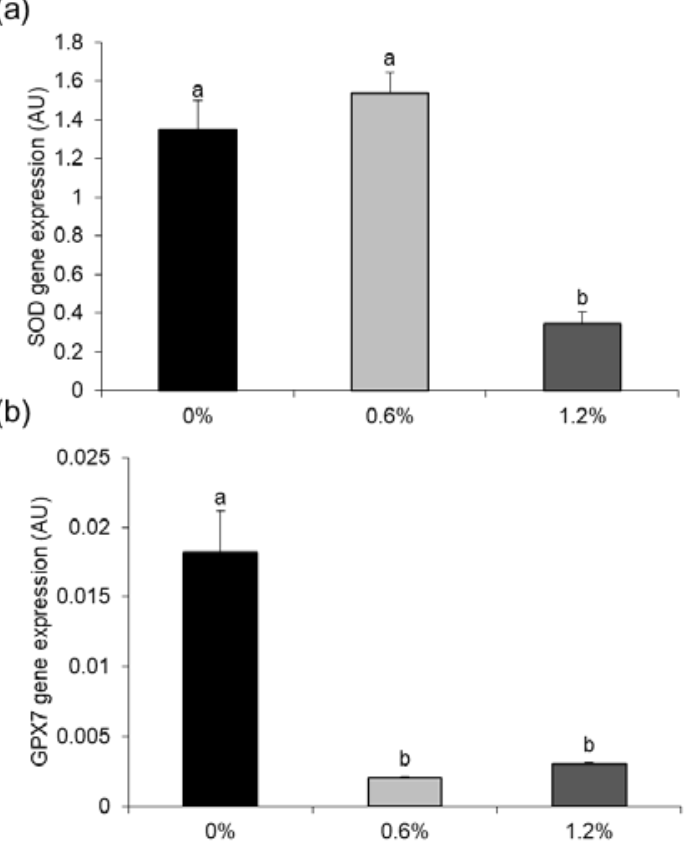

Figure 4 Superoxide dismutase (SOD) (a) and glutathione peroxidase 7 (GPX7) (b) gene expression in duodenum of quails receiving diets containing $0 \%, 0.6 \%$ or $1.2 \%$ citric acid

Glucose is absorbed by the active transport $\mathrm{Na}^{+}$dependent, sodium glucose cotransporter, SGLT1. Glucose leaves the cell into blood by facilitated diffusion through the GLUT2 in the basolateral membrane, or by independent processes (Mueckler \& Thorens, 2013). Gilbert et al. (2007) evaluated the expression of intestinal transporters by absolute quantification, and observed that quantities of GLUT2 mRNA increased with age. However, GLUT2 was the least expressed gene compared with the other sugar transporters, 60 to 2300 molecules of GLUT2 mRNA per nanogram of total RNA. Quantities of SGLT1 mRNA ranged from 1200 to 63300 molecules per nanogram of total RNA. This could be a reason for the current results. No effect of treatments on GLUT2 gene expression was observed.

Small peptides and free amino acids are the products of protein digestion. The peptide carrier $-\mathrm{H}^{+}$ dependent, Pept 1 , is responsible for the efficient absorption of di-and tri-peptides. The amino acids have specific carriers for absorption. Amino acid carriers can be classified according to the affinity with substrates, that is, anionic, neutral or cationic amino acids, and for the sodium dependence. Among these carriers, amino acid transporter $\mathrm{B}^{0} \mathrm{AT} 1$ is a neutral amino acid transporter that is sodium dependent, and is present in the brush border ( $\mathrm{Wu}, 2013)$.

Studies showed that the expression of glucose and amino acids transporters may be influenced by age, the intestine segment (Miska et al., 2015), the line (Zeng et al., 2011) and even heat stress (Sun et al., 2015). Su et al. (2014) observed that birds infected with Eimeria acervulina showed lower expression not only of intestinal carriers but also of the antimicrobial peptide, LEAP2 (liver-expressed antimicrobial peptide 2). It is suggested that the lower expression of $L E A P 2$ could lead to a lower expression of amino acid transporters, resulting in a reduced intracellular amino acid pool, thus a lower energy source to infected cells, preventing replication of the pathogen. The observation of this result suggests that the greatest expression of intestinal carriers observed in the current study in citric acid-fed birds may be related to possible control of pathogenic bacteria in the birds.

Since the processes of digestion and absorption, which are influenced by the microorganisms, determine the capacity of the animal to convert the diet into muscle, perfect matches between the communities in the intestines and between the microorganisms and the host are essential for intestinal health, and thus for efficient development of the bird (Rinttilä \& Apajalahti, 2013). Among other factors, the components of a diet have a large effect on the composition of the microbial population (Yeoman \& White, 2014). Thus, additives such as organic acids have been studied as potential antimicrobial modulators. The beneficial action of acids may be due to i) the reduction in $\mathrm{pH}$ of the medium, which acts against the growth 
of pathogenic bacteria, which are usually sensitive to acidic $\mathrm{pH}$, such as Escherichia coli and Salmonella sp. (Milillo \& Ricke, 2010), ii) the role of organic acids in increasing the beneficial communities, and iii) the improved pancreatic secretion, and thus digestion of nutrients (Dibner \& Buttin, 2002), among others.

Studies that have been conducted to elucidate how microorganisms from the GIT may act in metabolic signalling, and thus in host response, showed that microbial-elicited ROS could act as a second messenger and trigger actions involved in growth, differentiation and motility of epithelial cells, and immune response in the host (Jones et al., 2012), which are important processes for GIT digestive and absorptive ability.

Reactive oxygen species include molecules with free radicals such as superoxide $\left(\mathrm{O}_{2}^{-}{ }^{-}\right)$and the hydroxyl radical $\left(\mathrm{OH}^{-}\right)$and molecules non-radical, $\mathrm{H}_{2} \mathrm{O}_{2}$. The high production of ROS by non-phagocytic cells is usually associated with metabolic disorders. However, in the GIT, besides the signalizing function, ROS are crucial to the elimination of phagocytosed pathogens. Phagocytes recognize some bacteria through molecular patterns. Once phagocytized, these would be eliminated by the action of ROS that are produced in the respiratory burst. To maintain homeostasis and to combat harmful ROS effects, mucosal cells have antioxidant systems, such as SOD, catalase and thioredoxin enzymes, together with the glutathione complex. Thus, in the intestinal environment, phagocytes that eliminate pathogenic bacteria, use ROS, and antioxidants are responsible for neutralizing the ROS produced with this function (Paiva \& Bozza, 2014).

Studies showed that the amount of ROS that is produced is influenced by the species of microorganism, not only by the amounts of microorganisms (Wu et al., 2009). It was observed that animals that were fed citric acid in their diet, showed less expression of the genes related to antioxidant capacity, SOD and GPX7, suggesting that animals that receive citric acid could present lower amounts of bacteria, possibly pathogenic, which require lower ROS production for disposal, and thus less expression or activity of antioxidants to combat ROS.

In general, the current results show that citric acid supplementation may have caused a better intestinal environment in which more nutrients and energy were available to ensure greater feed efficiency. If the levels of supplementation are compared, although there was no difference in the feed conversion ratio and in the expression of $B^{0} A T 1$ and GPX7 genes between quails fed $0.6 \%$ and $1.2 \%$ of citric acid supplementation, birds fed $0.6 \%$ of citric acid had the highest weight gain. According to Islam et al. (2012), the inclusion of citric acid in lower doses would be useful for sanitary aspects and gut health, resulting in decreased colonization of pathogens and production of toxic metabolites. These authors recommend up to $0.75 \%$ in pelleted feed and $0.5 \%$ in mash diets, with a safety margin of $6.0 \%$ in diets for broiler chickens. Additional studies are necessary to better understand the effect of various levels of citric acid supplementation on the metabolism of quails.

\section{Conclusion}

Quails receiving citric acid in their diets showed less expression of genes related to antioxidant capacity, increased expression of the SGLT1 gene, which is responsible for glucose absorption, and increased expression of the gene $B^{O} A T 1$, which is responsible for the absorption of amino acids. These results may have contributed to the greater weight gain and lower feed intake that were observed in birds fed diets supplemented with $0.6 \%$ citric acid.

\section{Acknowledgements}

This study was financially supported by the National Council for Scientific and Technological Development CNPq, Brazil. This study was financed in part by the Coordenação de Aperfeiçoamento de Pessoal de Nível Superior Brasil (CAPES) - Finance Code 001.

\section{Authors' Contributions}

APDV and TPS designed the study, conducted the laboratory analysis and did the final drafting. JASJ, MSB, CSN, carried out the laboratory analysis and manuscript drafting. ASN, COB and GMOJ conducted the animal experiment and manuscript drafting. LTB and EG carried out the data analysis and manuscript drafting.

\section{Conflict of Interest Declaration}

The authors declare that they have no competing interests.

\section{References}

Adil, S., Banday, T., Bhat, G.A., Mir, M.S. \& Rehman, M., 2010. Effect of dietary supplementation of organic acids on performance, intestinal histomorphology, and serum biochemistry of broiler chicken. Vet. Med. Int. doi: http://dx.doi.org/10.4061/2010/479485.

Brestoff, J.R. \& Artis, D., 2013. Commensal bacteria at the interface of host metabolism and the immune system. Nat. Immunol. 14, 676-684.

Dibner, J.J. \& Buttin, P., 2002. Use of organic acids as a model to study the impact of gut microflora on nutrition and metabolism. J. Appl. Poult. Res. 11, 453-463. 
Forder, R.E.A., Howarth, G.S., Tivey, D.R. \& Hughes, R.J., 2007. Bacterial modulation of small intestinal goblet cells and mucin composition during early post hatch development of poultry. Poult. Sci. 86, 2396-2403.

Gilbert, E.R., Li, H., Emmerson, D.A., Webb, K.E. \& Wong, E.A., 2007. Developmental regulation of nutrient transporter and enzyme mRNA abundance in the small intestine of broilers. Poult. Sci. 86, 1739-1753.

Gong, J., Si, W., Forster, R.J., Huang, R., Yu, H., Yin, Y., Yang, C. \& Han, Y., 2007. 16S rRNA gene-based analysis of mucosa-associated bacterial community and phylogeny in the chicken gastrointestinal tracts: From crops to ceca. FEMS Microbiol. Ecol. 59, 147-157.

Hassan, H., Mosaad, G.M.M. \& Abd-Ellah, A.E.M., 2016. Effect of feeding citric acid on performance of broiler ducks fed different protein levels. J. Adv. Vet. Anim. Res. 6, 18-26.

Islam, K., 2012. Use of citric acid in broiler diets. World's Poult. Sci. J. 68 (1), 104-118. doi:10.1017/S0043933912000116

Jones, M.R., Mercante, W.J. \& Neish, S.A., 2012. Reactive oxygen production induced by the gut microbiota: Pharmacotherapeutic implications. Curr. Med. Chem. 2012; 19, 1519-1529.

Milillo, S.R. \& Ricke, S.C., 2010. Synergistic reduction of Salmonella in a model raw chicken media using a combined thermal and acidified organic acid salt intervention treatment. J. Food Sci. 75, 121-125.

Miska, K.B., Fetterer, R.H. \& Wong, E.A., 2015. mRNA expression of amino acid transporters, aminopeptidase, and the di-and tri-peptide transporter PepT1 in the intestine and liver of posthatch broiler chicks. Poult. Sci. https://doi.org/10.3382/ps/pev059.

Mueckler, M. \& Thorens, B., 2013. The SLC2 (GLUT) family of membrane transporters. Mol. Aspects Med. 34, $121-138$.

Paiva, C.N. \& Bozza, M.T., 2014. Are reactive oxygen species always detrimental to pathogens? Antioxid. Redox. Signa. 20, 1000-1037.

Ranjitkar, S., Lawley, B., Tannok, G. \& Engberg, R.M., 2016. Bacterial succession in the broiler gastrointestinal tract. Appl. Environ. Microbiol. 82, 2399-2410.

Reece, W.O., Erickson, H.H., Goff, J.P. \& Uemura, E.E., 2015. Duke's Physiology of Domestic Animals. Wiley-Blackwell, Ames, IA., USA.

Rinttilä, T. \& Apajalahti, J., 2013. Intestinal microbiota and metabolites - Implications for broiler chicken health and performance. J. Appl. Poult. Res. 22, 647-658.

Rodríguez-Lecompte, J.C., Yitbarek, A., Brady, J., Sharif, S., Cavanagh, M.D., ..., Camelo-James, L., 2012. The effect of microbial-nutrient interaction on the immune system of young chicks after early probiotic and organic acid administration. J. Anim. Sci. 90, 2246-2254.

Rostagno, H.S., Albino, L.F.T., Donzele, J.L., Gomes, P.C., Oliveira, R.F., Lopes, D.C., Ferreira, A.S., Barreto, L.S.T. \& Euclides, R.F., 2011. Brazilian tables for poultry and swine: Composition of feedstuffs and nutritional requirements 3rd edition. Minas Gerais, 2011.

Su, S., Miska, K.B., Fetterer, R.H., Jenkins, M.C. \& Wong, E.A., 2014. Expression of digestive enzymes and nutrient transporters in Eimeria acervulina-challenged layers and broilers. Poult. Sci. 93, 1217-1226.

Sun, X., Zhang, H., Sheikhahmadi, A., Wang, Y., Jiao, H., Lin, H. \& Song, Z., 2015. Effects of heat stress on the gene expression of nutrient transporters in the jejunum of broiler chickens (Gallus gallus domesticus). Int. J. Biometeorol. 59, 127-135.

Wu, G., 2013. Amino acids - Biochemistry and Nutrition. CRC Press, Boca Raton, FL., USA.

Wu, W., Hsu, Y.M., Bi, L., Songyang, Z. \& Lin, X., 2009. CARD9 facilitates microbe-elicited production of reactive oxygen species by regulating the LyGDI-Rac1 complex. Nat. Immunol. 10, 1208-1214.

Yeoman, C.J. \& White, B.A., 2014. Gastrointestinal tract microbiota and probiotics in production animals. Annu. Ver. Anim. Biosci. 2, 469-486.

Zeng, P.L., Li, X.G., Wang, X.Q., Zhang, D.X., Shu, G. \& Luo, Q.B., 2011. The relationship between gene expression of cationic and neutral amino acid transporters in the small intestine of chick embryos and chick breed, development, sex, and egg amino acid concentration. Poult. Sci. 90, 2548-2556. 